\title{
Investigation of the Failure of Parenterally Administered Haloperidol to Antagonize Dopamine Released from Micropipettes in the Caudate
}

\author{
Steven W. Johnson, ${ }^{\star}$ Barry J. Hoffer, ${ }^{\star}$ and Robert Freedman ${ }^{\star} \dagger \neq$ \\ Departments of *Pharmacology and †Psychiatry, University of Colorado Health Sciences Center, Denver,

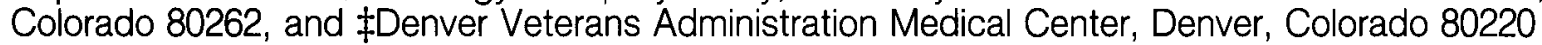

An anomaly in the experimental data underlying the theory that neuroleptics act by blockade of dopaminergic neurotransmission is the repeatedly demonstrated failure in several laboratories of parenterally administered neuroleptics to antagonize electrophysiologic actions of locally applied dopamine (DA) in striatum. This failure is enigmatic since many investigators have successfully demonstrated antagonism when both dopamine and neuroleptic are applied directly to striatal neurons by microiontophoresis. We used multibarrel micropipettes to pressure-eject DA agonists onto rat caudate neurons while observing the ability of parenterally administered haloperidol to block the inhibitory actions of dopaminergic agonists on neuronal activity. Experiments performed at times of maximal behavioral effect of haloperidol did not demonstrate agonist-antagonist interaction. This result has been obtained by four other teams of investigators. A variety of pharmacologic manipulations were employed to help solve this enigma. Acute treatment with reserpine and $\alpha$-methyl-paratyrosine, performed to minimize any possible interference by endogenous DA, did not permit blockade of dopamine by haloperidol. To see if this failure of antagonism could be generalized to other DA agonists, apomorphine, amphetamine, and phencyclidine (PCP) were also investigated. Although the direct dopaminergic agonist apomorphine was not antagonized by haloperidol, the indirect DA agonist PCP was successfully antagonized. Amphetamine, which has both direct and indirect actions when applied locally, was not antagonized. Antagonism of direct agonists was demonstrated in rats with unilateral 6-hydroxydopamine-induced lesions of the nigrostriatal pathway. In these preparations, parenterally administered haloperidol reversed the receptor-mediated supersensitivity to the inhibitory effects of locally applied DA and apomorphine. These data suggest that in caudate there exist postsynaptic receptors that are more sensitive to haloperidol than those receptors usually activated by DA released into the neuronal milieu from micropipettes. We suggest that PCP's indirect action on endogenous DA in presynaptic terminals results in specific interaction with these receptors. We further suggest that the postsynaptic receptors most sensitive to blockade by haloperidol may also be those receptors that increase in number following denervation. Failure to demonstrate antagonism of direct $\mathrm{DA}$ agonists in the absence of supersensitivity suggests that locally applied DA does not normally contact postsynaptic dopami-

\footnotetext{
Received Oct. 25, 1984; revised Apr. 29, 1985; accepted May 24, 1985.

This work was supported by USPHS Grants DA-02429, NS-09199, and MH38321. We thank Dr. Nancy Zahniser for helpful discussions and Elaine Steffen for preparing the text.

Correspondence should be addressed to Dr. Freedman, Department of Psychiatry, C268, University of Colorado Health Sciences Center, 4200 E. Ninth Avenue, Denver, CO 80262.

0270-6474/86/020572-09\$02.00/0
}

nergic receptors, but rather extrasynaptic receptors with different pharmacologic characteristics.

Much evidence supports the hypothesis that neuroleptic agents produce antipsychotic and cataleptic effects via blockade of dopaminergic neurotransmission in the CNS. For example, clinically effective antipsychotic agents displace dopamine ligands from striatal binding sites (Creese et al., 1976); they block dopamine-stimulated adenylate cyclase in preparations of caudate homogenates (Clement-Cormier et al., 1974; Miller et al., 1974); and they increase striatal concentrations of DA metabolites (Bacopoulos and Roth, 1981; Carlsson and Lindquist, 1953). In behavioral paradigms, systemically administered apomorphine antagonizes neuroleptic-induced catalepsy (Kolbe et al., 1981). Further evidence is derived from electrophysiological experiments demonstrating that neuroleptic agents antagonize DAinduced inhibitions of activity of striatal neurons when both substances are administered by microiontophoresis (Siggins et al., 1974; York, 1972). However, when this experiment is altered so that the neuroleptic is administered parenterally while DA is delivered locally, antagonism cannot be demonstrated (BenAri and Kelly, 1976; Skirboll and Bunney, 1979; Zarzecki et al., 1977). Failure to demonstrate antagonism has been observed with $\alpha$-flupenthixol $(10 \mathrm{mg} / \mathrm{kg}$, i.v.) and pimozide $(10 \mathrm{mg} / \mathrm{kg}$, i.v.) in cats (Ben-Ari and Kelly, 1976), and haloperidol at doses of $2.5 \mathrm{mg} / \mathrm{kg}$, i.v., in rats (Skirboll and Bunney, 1979) and 6$20 \mathrm{mg} / \mathrm{kg}$, i.p., in cats (Zarzecki et al., 1977). These doses of parenterally administered neuroleptic agents are more than sufficient for the production of catalepsy in laboratory animals (Janssen, 1973; Moller-Nielsen et al., 1973). Since neuroleptics are thought to antagonize effects of DA, and local release of DA from a micropipette presumably mimics release from synapses, it would seem that demonstration of antagonism in this context would be crucial to any theory concerning the mechanism responsible for behavioral effects of neuroleptic drugs. In fact, failure of systemically administered neuroleptics to block locally applied DA has led some investigators to suggest that the behavioral effects of these agents might not be due simply to generalized blockade of DA receptors at postsynaptic sites (BenAri and Kelly, 1976; Skirboll and Bunney, 1979).

We considered several possible reasons for the repeated failure to demonstrate antagonism with parenterally administered neuroleptics and designed a series of experiments accordingly. Protocols used by previous investigators (Ben-Ari and Kelly, 1976; Skirboll and Bunney, 1979; Zarzccki ct al., 1977) may have contributed to the failure to demonstrate antagonism of effects of locally applied DA by parenteral neuroleptics. For example, all previous studies used microiontophoresis to deliver DA dissolved in solutions unprotected against possible oxidation. Therefore, in the present study we utilized pressure-microejec- 
tion as an alternative to microiontophoresis to eliminate the possibility that failure to observe antagonism was somehow an artifact caused by iontophoretic currents. We also added ascorbate to DA solutions to prevent oxidation reactions. We chose to study the neuroleptic, haloperidol, and constructed a paradigm in which experiments were performed at time of peak behavioral effect. To obviate the possibility that presynaptic, endogenous stores of DA in some way interfered with the agonist-antagonist interaction, some experiments were performed in animals pretreated with reserpine and $\alpha$-methyl-paratyrosine. Other experiments used rats with unilateral 6-hydroxydopamine-induced lesions of the nigrostriatal pathway to investigate whether antagonism of locally applied DA could be demonstrated in striatum made supersensitive by denervation (Feltz and de Champlain, 1972; Ungerstedt and Arbuthnott, 1970). Finally, it was considered possible that the failure of parenterally administered neuroleptics to antagonize locally administered dopamine would not generalize to other DA agonists. Therefore, we also evaluated the ability of haloperidol to block the effects of other locally applied agonists. We examined apomorphine, which directly activates dopamine receptors (Anden et al., 1967); phencyclidine (PCP), which acts prcsynaptically to influence perhaps by blockade of dopamine uptake or enhancement of release dopamine receptors (Ary and Komiskey, 1982; Johnson et al., 1984; Vickroy and Johnson, 1983); and $d$-amphetamine, which has mixed characteristics (see Discussion). In the present study we successfully demonstrate antagonism of effects of locally applied DA agonists by parenterally administered haloperidol. We suggest that the experimental conditions necessary for the demonstration of the agonist-antagonist interactionuse of an indirect agonist or a denervation of dopaminergic input to the caudate-may provide insight into the site of action of neuroleptic drugs and the potential limitations in the analogy of local release of agents by micropipettes to actual synaptic neurotransmission.

\section{Materials and Methods}

\section{Surgery}

Male Sprague-Dawley rats (200-400 gm) were anesthetized with urethane (1.25 mg/kg, i.p.; Sigma Chemical Co., St. Louis, MO), intubated, and allowed to breathe spontaneously. Body temperature was maintained at $36-37^{\circ} \mathrm{C}$ with a heating pad. After drainage of cerebrospinal fluid from the cisterna magna, a portion of the skull and dura was removed, extending from $1 \mathrm{~mm}$ posterior to $5 \mathrm{~mm}$ anterior of bregma, and from 1 to $3 \mathrm{~mm}$ lateral of midline. The surface of the brain was covered with a suspension of $2 \%$ agar ( $w t / v o l)$ in saline.

\section{Electrophysiological methods}

Caudate neurons were recorded extracellularly with single- or multibarrel micropipettes. Corning (WPI, New Haven, CT) fiber-filled glass capillary tubing was used to assemble pipettes (Palmer et al., 1980). Tips of two- or three-barrel micropipettes were broken to diameters of 3 and $4 \mu \mathrm{m}$, respectively. The recording barrel was filled with $4 \mathrm{M} \mathrm{NaCl}$ or $3 \mathrm{M} \mathrm{NaCl}$ and $1 \mathrm{~m}$ glutamate to increase neuronal firing rates. All agonist and antagonist effects were observed with or without glutamate. Glutamate activation was not used in the 6-hydroxydopamine experiments. The remaining barrels were filled with drug solutions, which were applied locally by pressure ejection. Neuronal signals were amplified, filtered $(-3 \mathrm{~dB}$ at 300 and $10,000 \mathrm{~Hz}$ ), and displayed on an oscilloscope. Action potentials were separated from background activity and converted to constant voltage pulses by a window discriminator. To detect action potentials with low amplitude, the window discriminator was adjusted to allow the detection of neuronal activity with a minimal signal-to-noise ratio of $2: 1$. Ratemeter records of neuronal activity were obtained by connecting the output of the window discriminator, integrated over $2 \mathrm{sec}$ intervals, to a strip chart recorder. Caudate neurons were recorded $1-2 \mathrm{~mm}$ anterior to bregma, $3 \mathrm{~mm}$ lateral to midline, and 3-6 mm beneath the brain surface (Pellegrino et al., 1979).

\section{Local application of drugs}

The following drug solutions were pressure-ejected from multibarrel micropipettes: $10 \mathrm{~mm} d$-amphetamine sulfate (Sigma), $1 \mathrm{~mm}$ apomorphine $\mathrm{HCl}$ (APO; Sigma), 1 mM PCP-HCl (NIDA, Rockville, MD), and $5 \mathrm{~mm}$ DA-HCl (Sigma). These drugs were dissolved separately in $0.9 \%$ $\mathrm{NaCl}$ (wt/vol) at $\mathrm{pH}$ 6.5. To the DA and APO solutions, ascorbic acid $(5 \mathrm{~mm})$ was added to inhibit oxidation, and HEPES $(5 \mathrm{~mm})$ was added as a buffer (pH 6.5). $\mathrm{N}_{2}$, at pressures of $7-240 \mathrm{kPa}(1 \mathrm{psi}=6.895 \mathrm{kPa})$ was used for pressure-ejection.

\section{Saline control experiments}

Previous studies have shown that pressure-ejected saline can produce nonspecific effects on neuronal activity whose magnitude is related to both pressure and ejection time (Johnson et al., 1984). Therefore, preliminary experiments were performed to find optimal concentrations of drugs for pressure microejection. In these experiments, a drug solution (either DA, APO, PCP, or amphetamine) and drug vehicle (either saline or saline plus HEPES and ascorbate) were pressure-ejected from separate barrels of the same three-barrel micropipette assemblies, thereby allowing the evaluation of dose-related effects of both solutions on the same caudate neurons. To minimize pipette variability, at least seven pipette assemblies were used to record a maximum of two neurons with each pipette. At least two rats were used to evaluate each drug. Control experiments with DA and PCP were reported previously (Johnson et al., 1984); PCP (1 mM) and DA (4 mM) were more potent than their respective drug vehicles, with potency ratios of 7.4 and 6.3. APO (1 $\mathrm{mM})$ and amphetamine $(10 \mathrm{~mm})$ were also significantly more potent than their respective vehicles, with potency ratios of 9.3 and 11.2. These results suggested that effects of pressure-ejected drug solutions due to specific effects of drugs could be analyzed and separated from nonspecific effects of pressure-ejected drug vehicle. It should be emphasized that the technique is not sufficiently precise to permit comparison between agonists released from different pipette barrels; therefore, the effect of haloperidol treatment was always determined by using the same barrel to apply agonist before and after haloperidol administration.

\section{Dopamine depletion}

In order to study the effects of DA and APO in DA-depleted caudate nuclei, rats were pretreated with reserpine (CBA Pharmaceutical Co., Summit, NJ) and $\alpha$-methyl-paratyrosine (AMPT; Sigma), or 6-hydroxydopamine (6-OHDA; Sigma). Reserpine $(5 \mathrm{mg} / \mathrm{kg}$, i.p.) was injected 12 $\mathrm{hr}$ before and AMPT ( $100 \mathrm{mg} / \mathrm{kg}$, i.p.) $2 \mathrm{hr}$ before experiments. 6-OHDA was injected unilaterally into the right substantia nigra according to the method of Ungerstedt and Arbuthnott (1970). Briefly, rats were anesthetized with chloral hydrate $(4 \%)$ and placed in a stereotaxic frame with the incisor bar $2.4 \mathrm{~mm}$ below the interaural line. Eight micrograms of 6-OHDA ( $2 \mathrm{mg} / \mathrm{ml}$ in saline, with $0.2 \mathrm{mg} / \mathrm{ml}$ ascorbate) were injected into brain at a rate of $1 \mu \mathrm{l} / \mathrm{min}$ with a $10-\mu \mathrm{l} \mathrm{Hamilton}$ syringe. Stereotaxic coordinates were $4.2 \mathrm{~mm}$ posterior to bregma, $1.1 \mathrm{~mm}$ lateral to midline, and $7.5 \mathrm{~mm}$ below the dura. After the needle was removed, the skull defect was covered with bone wax, the skin incision was closed with wound clips, and the animal was given 30,000 units of penicillin subcutaneously (s.c.). All lesioned rats used for electrophysiological studies were shown to have pronounced rotation away from the lesioned side following apomorphine treatment $(0.2 \mathrm{mg} / \mathrm{kg}$, s.c.), which is indicative of significant unilateral depletion of DA and subsequent receptor supersensitivity in the striatum (Heikkila et al., 1981; Marshall and Ungerstedt, 1977; Perlow et al., 1979). Effects of pressure-ejected drugs on caudate neuronal activity were studied 6-8 weeks after 6-OHDA lesions were made.

\section{Data analysis}

Ratemeter records were analyzed to obtain the percentage change in spontaneous neuronal activity produced by drug application, as described previously (Palmer and Hoffer, 1980). Ratemeter traces were digitized using a Tektronix graphics tablet and were led to a NOVA 3/12 computer (Data General, Southboro, MA). Digitized data were stored and subsequently displayed on a Tektronix CRT computer terminal. Vertical vectors were then superimposed over the display and were used to analyze neuronal activity before, during, and after drug applications. The area under the curve during drug response, divided by the duration of response, was analyzed as a percentage of change from the averaged area (mean spikes/sec) under the curve from an equal 
length control epoch preceding the drug response. These results were then quantified as a percentage decrease (or increase) of spontaneous neuronal activity elicited by application of drug. Identical control and response epochs were used for analysis of agonist response before, during, and after antagonist administration.

\section{Construction and analysis of dose-response curves}

Pressure-ejection from glass micropipettes has been reported to release drug in an amount linearly releated to the product of pressure and duration of ejection (McCaman et al., 1977; Sakai et al., 1979). The magnitude of drug effect has also been reported to be a function of these parameters of pressure-ejection (Palmer et al., 1980). Therefore, in the present study, dose-response relationships for pressure-ejected drugs were studied, where "dose" was expressed as the product of pressure $(\mathrm{kPa})$ and time $(\mathrm{sec})$. To permit averaging of responses from many neurons, the following standard "doses" $(\mathrm{kPa} \times \mathrm{sec})$ were employed: $7 \times 1,17 \times 1,17 \times 2,34 \times 2,34 \times 5,69 \times 5,69 \times 10,138 \times 10$, $138 \times 20$, and $240 \times 23$. (In psi, the products of these numbers are 1 , $2.5,5,10,25,50,100,200,400$, and 800.) All dose-response curves were analyzed statistically by linear regression analysis (Tallarida and Jacob, 1979) after transformation of data to Hill-plot coordinates (Changeux and Podleski, 1968). Slope, $\mathrm{ED}_{50}$, and $95 \%$ confidence limits were calculated for each dose-response curve. Parallelism was tested before any two dose-response curves were compared for differences in potency. Differences between slopes and $\mathrm{ED}_{50}$ 's were considered significant if $95 \%$ confidence limits did not overlap.

\section{Experiments with "paired" rats}

Potencies of pressure-ejected drugs from the same pipette were compared concurrently in control rats and rats treated with haloperidol (McNeil Pharmaceuticals, Springhouse, PA) either before or after anesthesia. In paired experiments, a control and haloperidol-trcatcd rat were anesthetized, prepared surgically as described above, and placed in separate, adjacent stereotaxic frames. To avoid errors due to pipette varability, the same pipettes were used to record neurons from control and drug-treated preparations. In the first rat, one neuron was recorded, then the pipette was moved to record two neurons in the second rat, after which the pipette was returned to record two more neurons in the first rat, etc. As a result, data from neurons were "paired" in terms of temporal contiguity and ejection characteristics of pipettes. This method of recording was also used to test the effects of DA and apomorphine in rats lesioned unilaterally with 6-OHDA. However, in these experiments, pipettes were moved from one side to the other in order to record neurons from both caudates in the same rat before and after haloperidol. In all experiments, care was taken to move pipettes from control to drug-treated caudatc as often as from the drug-treated to the control caudate.

\section{Haloperidol time-effect relationship}

When haloperidol is administered in sufficient doses, rats will maintain unusual postures for relatively long durations (Moller-Nielsen et al., 1973). This behavior was utilized in defining the time-effect relationship for haloperidol. Rats were placed standing upright on hindlimbs while supported by their forelimbs on a wire suspended horizontally $20 \mathrm{~cm}$ above the floor. The length of time rats maintained this posture was counted as the time spent "immobile." Rats were given either saline $(0.5 \mathrm{ml}$, i.p.) or haloperidol ( $1 \mathrm{mg} / \mathrm{kg}$, i.p.), and "immobility" was measured before and at various times after injection.

\section{Results}

As has been reported in previous studies from our laboratory (Johnson et al., 1983, 1984), 80-90\% of caudate neurons tested with pressure-ejected DA showed inhibition of spontaneous activity. In preliminary experiments in four rats, haloperidol, at doses of $0.5-5 \mathrm{mg} / \mathrm{kg}$, i.p., failed to antagonize this effect of DA. Repeated administrations of DA were performed at $1 \mathrm{~min}$ intervals on the same neuron for up to $90 \mathrm{~min}$ after haloperidol injection without significant change in agonist effect.

Because many neuroleptic agents are known to have prolonged actions (Moller-Nielsen et al., 1973), it is possible that 90 min was insufficient to observe maximal effects of haloperidol. To define the time-effect curve, rats were treated with

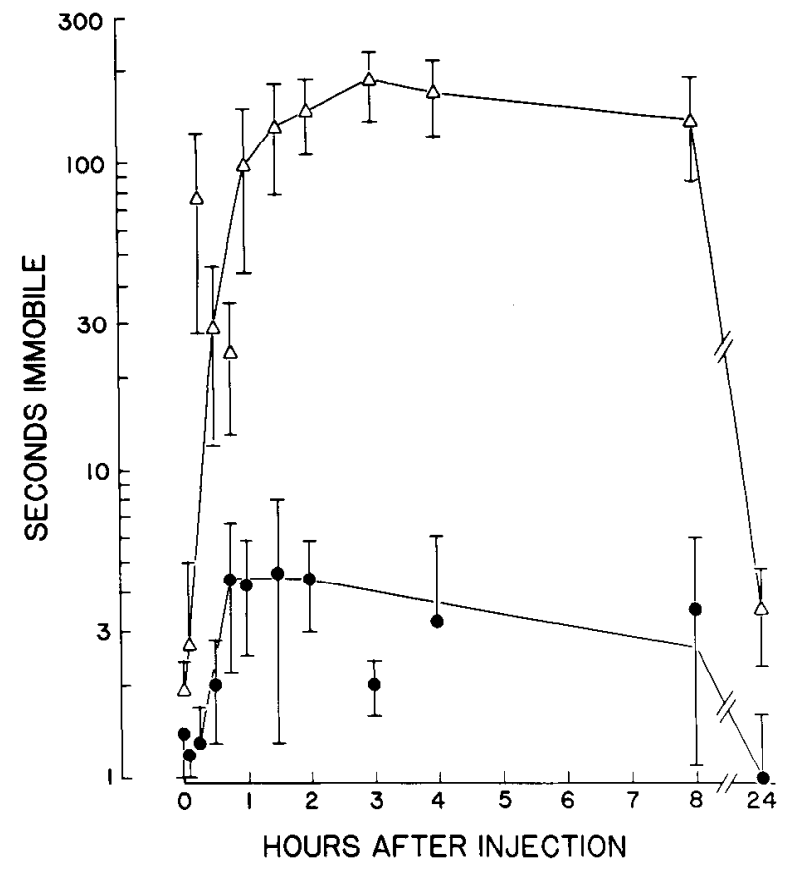

Figure 1. Time-effect curve for immobility induced by haloperidol. Immobility was measured as the time during which rats stood upright on hindlimbs while forelimbs grasped a string suspended horizontally $20 \mathrm{~cm}$ above the floor. Data points represent the mean $( \pm$ SEM) response of seven rats treated with haloperidol $(\Delta), 1 \mathrm{mg} / \mathrm{kg}$, i.p., and four control rats that received $0.5 \mathrm{ml}$ of saline (@), i.p. Data at "zero" hours represent pretreatment control measurements. Although both groups showed an increase in duration of immobility after repeated testing, rats treated with haloperidol were immobile for significantly longer times than control rats from $15 \mathrm{~min}$ to $8 \mathrm{hr}$ after injection $(p<0.001$; two-tailed Student's $t$ test).

haloperidol ( $1 \mathrm{mg} / \mathrm{kg}$, i.p.) or saline, and tested repeatedly for immobility, as explained in Methods. Results of this study are shown in Figure 1. Before injections, animals stayed suspended by the wire for only 1 or $2 \mathrm{sec}$. Although control animals 1 and $2 \mathrm{hr}$ after saline injection were immobile for times that were significantly longer than those for pre-injection controls ( $p<$ 0.01 ; two-tailed $t$ test), this finding was probably an artifact of repeated testing. Rats treated with haloperidol were immobile significantly longer than were control rats: $15 \mathrm{~min}$ to $8 \mathrm{hr}$ after injection ( $p<0.001$; two-tailed $t$ test). Peak drug effect occurred betwcen 2 and $4 \mathrm{hr}$ after haloperidol administered by intraperitoneal injection. Twenty-four hr after injection, immobility times in rats treated with haloperidol approached values of control rats.

In order to establish whether the effects of DA might be antagonized by haloperidol 1-8 hr after injection, studies were performed with pairs of rats, one treated with haloperidol and one that served as control. This protocol was used because of the technical difficulty of studying an individual neuron for such long time periods. In experiments with pressure-ejected DA, eight two-barrel micropipettes were used to record 20 neurons in control rats and 20 neurons in rats pretreated with haloperidol. Four pairs of rats were used in this study, and neurons were "paired," as described in Methods. Neurons in haloperidol-treated rats were recorded $6.2 \pm 2.2 \mathrm{hr}(\bar{X} \pm \mathrm{SD})$ after injection. Despite recording at times during which haloperidol was known to be active behaviorally, there was no significant difference between the potency of DA in control rats and that in rats pretreated with haloperidol. The $\mathrm{ED}_{50}$ 's and $95 \%$ confidence limits from these data are listed in Table 1. For these experiments, DA was administered either in a buffered solution, with ascorbate as an antioxidant, or in saline alone. While ascor- 

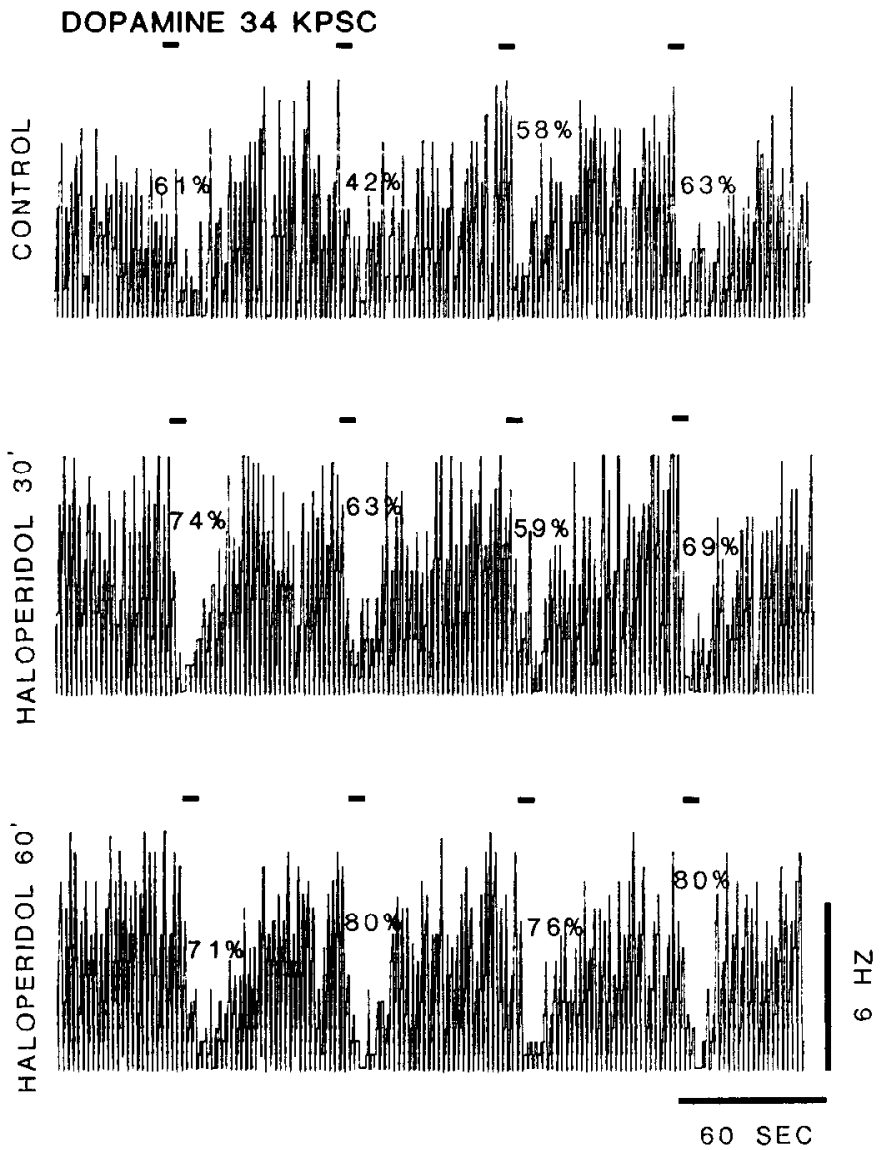

Figure 2. Ratemeter records from a single caudate neuron showing effects of pressure-ejected dopamine (DA) before and after haloperidol $(1 \mathrm{mg} / \mathrm{kg}$, i.p.). This rat was treated with reserpine $(5 \mathrm{mg} / \mathrm{kg}, \mathrm{i} . \mathrm{p}$. $) 12 \mathrm{hr}$ before, and with $\alpha$-methyl-paratyrosine $(100 \mathrm{mg} / \mathrm{kg}$, i.p.) $2 \mathrm{hr}$ before this experiment. Bars above ratemeter records indicate durations of DA application, while percentages represent percentage decrease in neuronal activity produced by DA. These data show no antagonism of effects of DA 30-60 min after haloperidol injection.

bate prevents oxidation of DA, it has also been reported to interfere with the binding of neuroleptics to DA receptors (Heikkila et al., 1982). However, with or without ascorbate, haloperidol (i.p.) failed to antagonize effects of locally applied dopamine (Table 1).

To help minimize the possibility that endogenous release of DA was in some way interfering with the ability of haloperidol to block effects of locally administered DA, this study was repeated in three rats pretreated with reserpine $(5 \mathrm{mg} / \mathrm{kg}$, i.p. $) 12$ $\mathrm{hr}$ before, and $\alpha$-methyl-paratyrosine $(100 \mathrm{mg} / \mathrm{kg}$, i.p. $) 2 \mathrm{hr}$ be-
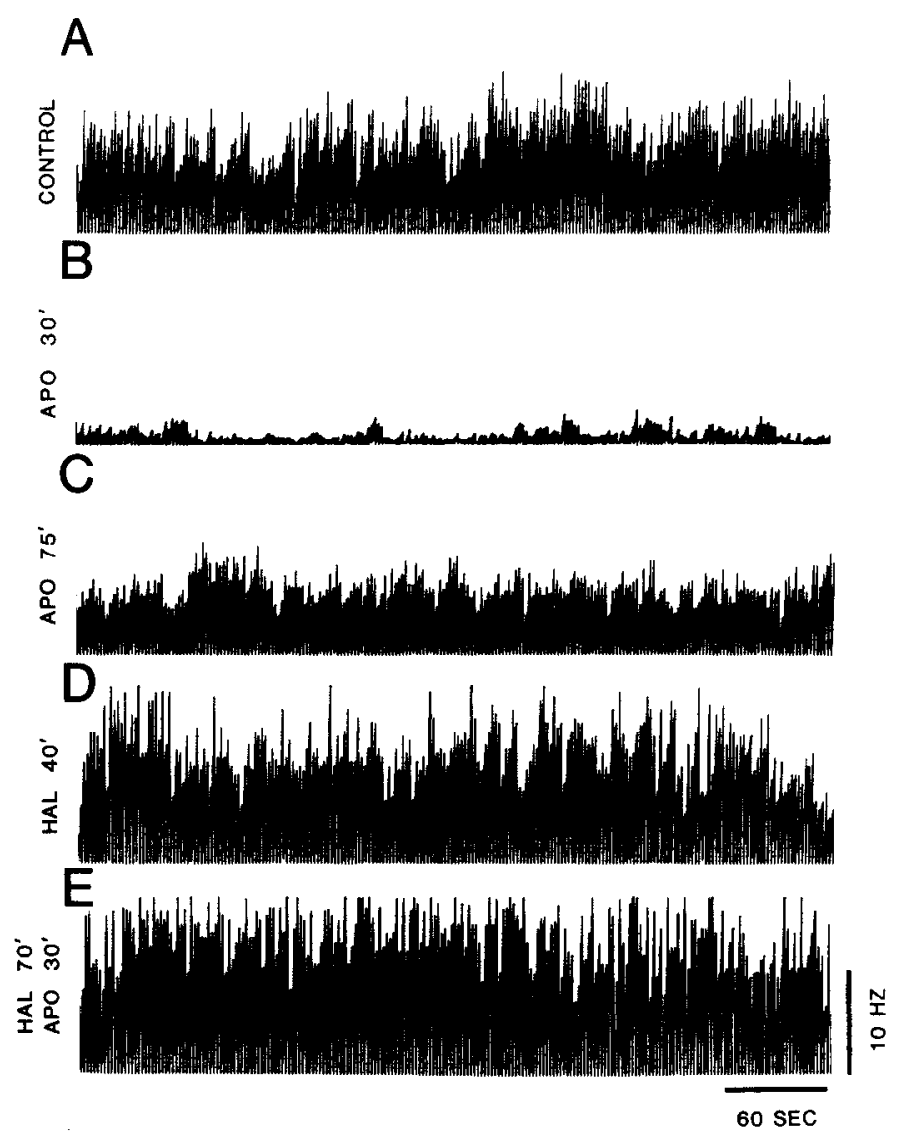

Figure 3. Ratemeter records from a single caudate neuron, demonstrating antagonism of effects of apomorphine $(A P O)$ by haloperidol $(H A L)$. Both drugs were injected i.p. Record $A$ shows spontaneous firing rate before APO. $B$, Rate $30 \mathrm{~min}$ after $A P O, 5 \mathrm{mg} / \mathrm{kg}$; activity decreased by approximately $90 \%$. C, Partial recovery $75 \mathrm{~min}$ after APO; at this time, haloperidol, at a dose of $1 \mathrm{mg} / \mathrm{kg}$, was injected. $D$, Spontaneous activity $\mathbf{4 0} \mathrm{min}$ after haloperidol. At this time, a second dose of APO $(5 \mathrm{mg} / \mathrm{kg})$ was injected; $30 \mathrm{~min}$ after the second dose of APO (70 min after haloperidol), the rate of spontaneous activity was unchanged $(E)$.

fore the effect of locally administered DA was tested. Results of one experiment are illustrated in Figure 2. Haloperidol (1 $\mathrm{mg} / \mathrm{kg}$, i.p.) failed to antagonize effects of DA up to $1 \mathrm{hr}$ after injection. Additional doses of 1,2 , or $5 \mathrm{mg} / \mathrm{kg}$ haloperidol, up to a cumulative dose of $10 \mathrm{mg} / \mathrm{kg}$, failed to antagonize effects of DA up to $90 \mathrm{~min}$ after the last injection.

APO, a DA agonist effective after parenteral administration, was subsequently investigated. At doses of $0.5-5 \mathrm{mg} / \mathrm{kg}$, i.p., APO was injected while neuronal firing rates were monitored with single-barrel micropipettes. These doses of APO were shown

Table 1. Effects of locally applied dopaminergic agonists in control and haloperidol-treated rats

\begin{tabular}{|c|c|c|c|c|c|c|}
\hline \multirow[b]{2}{*}{ Drug } & \multirow[b]{2}{*}{ Vehicle } & \multicolumn{2}{|c|}{ Control $^{a}$} & \multicolumn{2}{|c|}{ Haloperidol } & \multirow{2}{*}{$\begin{array}{l}\text { Po- } \\
\text { tency } \\
\text { ratio }\end{array}$} \\
\hline & & $\mathrm{ED}_{50}$ & 95\% Limits & $\mathrm{ED}_{50}$ & 95\% Limits & \\
\hline Dopamine & Saline & 254 & $201-322$ & 252 & $195-324$ & 1.0 \\
\hline Dopamine & $\begin{array}{l}\text { Saline, HEPES, } \\
\text { ascorbate }\end{array}$ & 186 & $152-228$ & 251 & 204-308 & 1.4 \\
\hline Apomorphine & Saline & 50 & $16-159$ & 85 & $66-108$ & 1.7 \\
\hline Amphetamine & Saline & 256 & $197-333$ & 249 & $168-371$ & 1.0 \\
\hline Phencyclidine & Saline & 246 & $207-292$ & 853 & $824-883$ & $3.5^{b}$ \\
\hline
\end{tabular}

${ }^{a} \mathrm{ED}_{50}$ 's and $95 \%$ limits are in units of $\mathrm{kPa}$-sec.

${ }^{b} p<0.05$. 

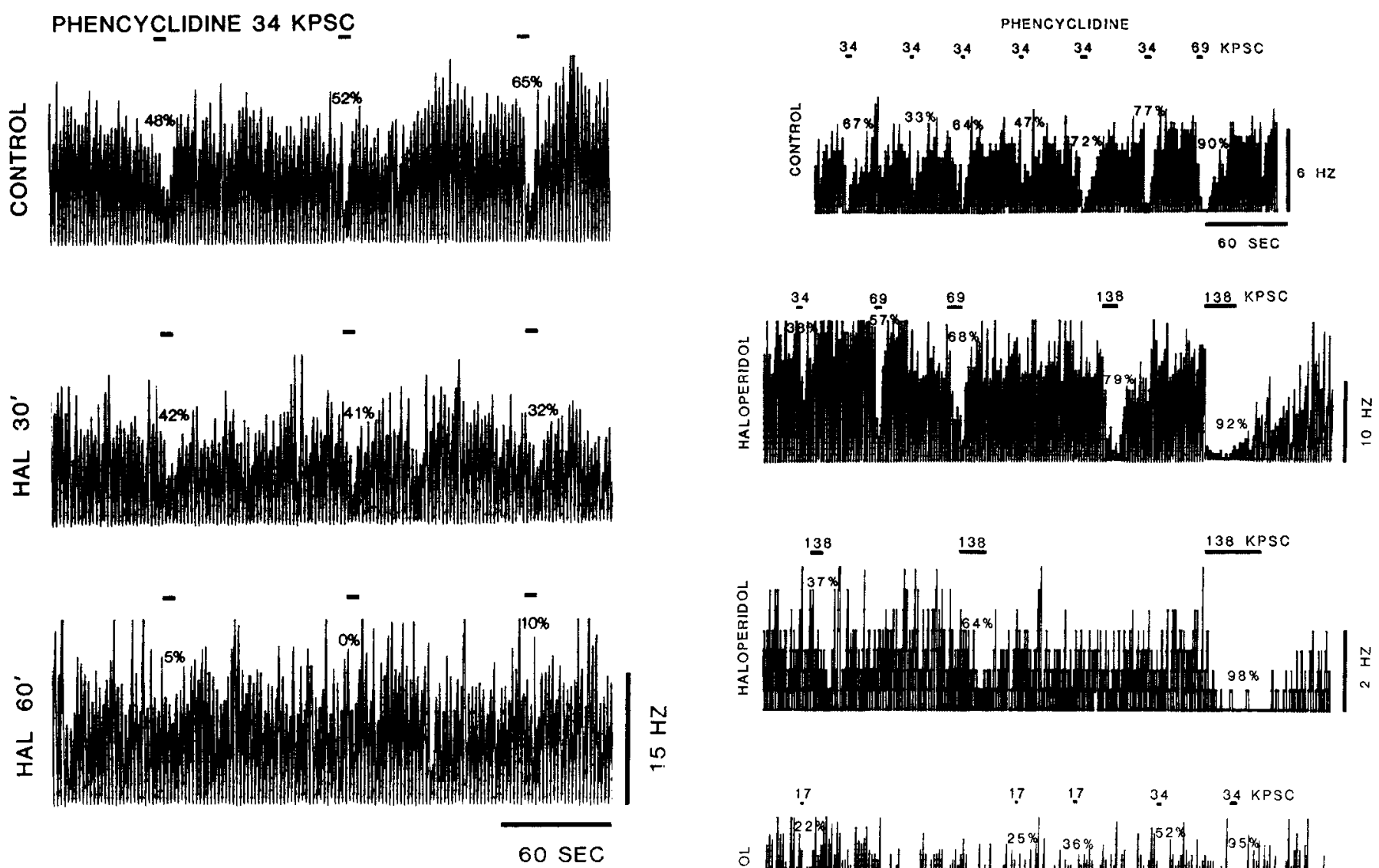

Figure 4. Ratemeter records from a single caudate neuron showing effects of pressure-ejected phencyclidine (PCP) before and after haloperidol $(1 \mathrm{mg} / \mathrm{kg}$, i.p.). Bars above ratemeter records indicate durations of PCP application, while percentages represent percentage decrease in neuronal activity produced by PCP. These data show virtually no effect of PCP 60 min after haloperidol injection. Although activity was monitored for an additional hour, effects of PCP did not recover.

previously to be effective in reversing neuroleptic-induced catalepsy (Bacopoulos and Roth, 1981; Moller-Nielsen et al., 1973), and in restoring eating and drinking after 6-OHDA treatment (Ungerstedt and Ljungberg, 1974). Results of one experiment are shown in Figure 3. After a latency of $15 \mathrm{~min}$, APO inhibited spontaneous firing for about $30 \mathrm{~min}$. As can also be seen in Figure 3, subsequent treatment with haloperidol $(1 \mathrm{mg} / \mathrm{kg}$, i.p.) completely blocked the effect of a second dose of APO. This result was seen in three animals. In control experiments, tachyphylaxis was not observed to a second dose of APO administered 90 min after the first.

Having established that haloperidol blocks effects of APO administered parenterally, the next experiments examined the ability of haloperidol ( $1 \mathrm{mg} / \mathrm{kg}$, i.p.) to block effects of APO administered locally by pressure-ejection. These experiments again utilized paired rats, one of which was pretreated with haloperidol, while the other scrved as control. Pipcttes were used to record "pairs" of neurons from both rats, as described in Methods. Six two-barrel micropipettes were used to record 28 neurons from two pairs of rats. The results, listed in Table 1 under "Apomorphine," showed that haloperidol administered $2-4 \mathrm{hr}$ before recording failed to antagonize significantly the effects of locally administered APO.

In order to investigate whether failure of haloperidol to block effects of locally applied drugs was limited to direct-acting DA agonists, experiments were performed with PCP, which is thought to act indirectly by causing release or blocking reuptake of DA (Bagchi, 1981; Garey and Heath, 1976; Johnson et al., 1984).

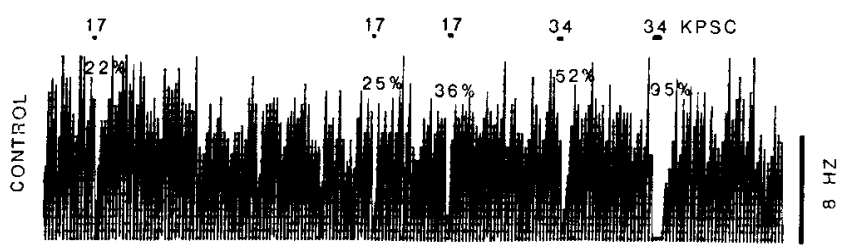

Figure 5. Ratemeter records showing dose-related effects of PCP on the activity of caudate neurons from a control rat and a rat pretreated 1-2 hr prior with haloperidol. A two-barrel micropipette was used to pressure-eject PCP and record the activity of the 4 neurons shown in this figure. Neurons were recorded sequentially. Bars above ratemeter records represent durations of PCP application, while percentages represent percentage decrease in spontaneous activity produced by PCP. In the uppermost record, $34 \mathrm{kPa}$ PCP, applied for $2 \mathrm{sec}$, caused a 33$64 \%$ reduction in neuronal activity in a control rat. The pipette was then moved to the rat pretreated with haloperidol, in which two neurons were recorded. In these two neurons, $50 \%$ reductions in activity were produced by $\mathrm{PCP}$ at pressures of $69-138 \mathrm{kPa}$ applied for 5-20 sec. The pipette was then moved back to the control rat to record the neuron shown lowermost in the figure. In this neuron, $52 \%$ reduction in activity was produced by $34 \mathrm{kPa}$ PCP applied for $2 \mathrm{sec}$. Thus, PCP was more potent in the control rat for inhibition of neuronal activity than in the rat pretreated with haloperidol.

In our first experiments, individual rats were given haloperidol $(1 \mathrm{mg} / \mathrm{kg}$, i.p.), while the responses of a single neuron to pressureejected PCP were recorded. The results, exemplified in Figure 4 , suggested that the effect of PCP was blocked by haloperidol 60-120 min after injection, as might be expected because of the long time course of haloperidol. Experiments were also performed with pairs of rats, with one of each pair treated with haloperidol, while the other served as control, to establish doseresponse curves. Figure 5 illustrates the findings in one experiment. The ratemeter record uppermost in the figure shows doserelated effects of pressure-ejected PCP on the spontaneous activity of a caudate neuron in a control rat. A PCP "dose" of 34 $\mathrm{kPa}$ applied for $2 \mathrm{sec}$ caused approximately a $50 \%$ reduction in activity. Next, the pipette was transferred to the rat treated with haloperidol, in which higher "doses" of PCP were necessary to 


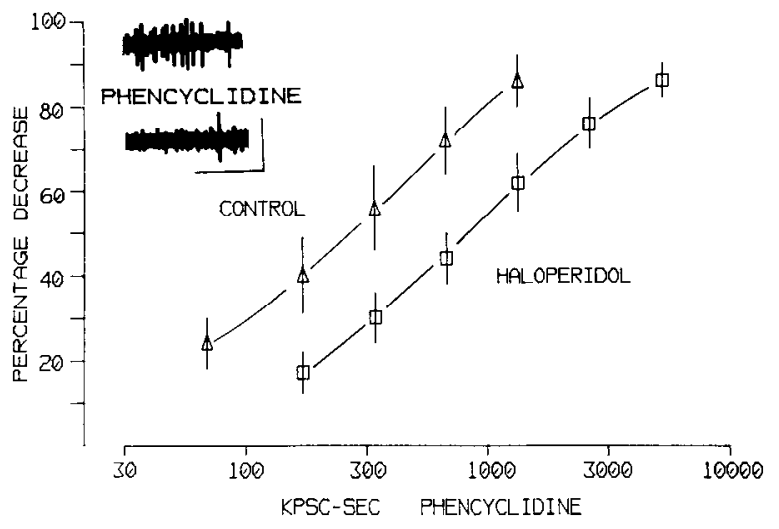

Figure 6. Dose-related effects of pressure-ejected phencyclidine (PCP) on spontaneous activity of caudate neurons in control rats (triangles) and rats treated with $1 \mathrm{mg} / \mathrm{kg}$ haloperidol (squares). Each data point represents the average response of 16 cells, while error bars represent SEM. These data were obtained from three pairs of rats with seven twobarrel micropipette assemblies. Pipettes were used to record neurons from pairs of rats, one serving as control and one treated with haloperidol, as described in Methods. Neurons were recorded $4.3 \pm 1.9 \mathrm{hr}$ $(\bar{X}+\mathrm{SD})$ after haloperidol injection. The $\mathrm{ED}_{s 0}$ (and 95\% confidence limits) of PCP was 246 (207-292) kPa-sec in control rats, and 853 (824$883) \mathrm{kPa}-\mathrm{sec}$ in rats treated with haloperidol. The potency ratio for PCP was 3.5. Inset, Oscilloscope record of a neuron before (upper trace) and during (lower trace) PCP administration ( $340 \mathrm{kPa}-\mathrm{sec})$, demonstrating the lack of nonspecific direct depressant effects of PCP on amplitude of action potentials. Vertical calibration, $0.25 \mathrm{mV}$; horizontal, $0.5 \mathrm{~S}$.

produce $50 \%$ reductions in activity. The first neuron recorded in the rat treated with haloperidol required a "dose" of $69 \mathrm{kPa}$ applied for 5 sec to produce a $57 \%$ change in activity. In the second neuron, $138 \mathrm{kPa}$ applied for $10-20 \mathrm{sec}$ was necessary to produce $50 \%$ reductions in activity. The pipette was then transferred back to the control rat to record the neuron shown in the ratemeter record lowermost in the figure. Similar to the first control neuron tested, a dose of $34 \mathrm{kPa}$ applied for $2 \mathrm{sec}$ caused an approximately $50 \%$ reduction in neuronal activity. Including the experiment shown in Figure 5, seven 2-barrel micropipettes were used to record 32 neurons in three pairs of rats. Doseresponse curves shown in Figure 6 illustrate the results of these experiments. The ED ${ }_{50}$ of PCP in control rats $(245 \mathrm{kPa}-\mathrm{sec})$ was significantly less than the $\mathrm{ED}_{50}$ obtained in rats treated with haloperidol $\left(853 \mathrm{kPa}\right.$-sec). The potency ratio $\left(\mathrm{ED}_{50,1} / \mathrm{ED}_{50,2}\right)$ showed that PCP was 3.5 times less effective in the haloperidoltreated rats. Results of these experiments are listed in Table 1.

Because it appeared that PCP, an indirect DA agonist agent, was antagonized by haloperidol, while the direct agonists DA and APO were not blocked, our study was extended to include amphetamine; this agent has properties of both a direct and indirect DA agonist (see Discussion). Amphetamine, dissolved in saline, was pressure-ejected while caudate neurons were recorded in pairs of rats $2-4 \mathrm{hr}$ after parenteral administration of haloperidol. Six two-barrel micropipettes were used to record 20 neurons in two pairs of rats. The results, listed in Table 1 , showed no significant difference in potency of amphetamine in control and haloperidol-treated rats.

Finally, the ability of haloperidol to antagonize effects of DA and APO was tested in caudate nuclei lesioned with 6-OHDA. Four rats with unilateral 6-OIIDA lesions were used, and each pipette assembly was used to record neurons from both caudate nuclei. Seven three-barrel micropipettes were used to record 32 neurons before haloperidol, while the same number of pipettes were used to record 34 neurons after $1 \mathrm{mg} / \mathrm{kg}$ haloperidol, i.p. Before halopcridol, the spontancous firing rate in lesioned caudate (11.2 \pm 3.8 spikes $/ \mathrm{sec}, \bar{X} \pm \mathrm{SD}, n=16)$ was significantly higher than the rate in control caudate $(5.4 \pm 2.6$ spikes $/ \mathrm{sec}$, $n=16, p<0.001$; paired $t$ test). Firing rates, measured $3.1+$ $1.7 \mathrm{hr}$ after haloperidol injection, were no longer significantly different: $9.7 \pm 3.6$ spikes $/ \mathrm{sec}$ in lesioned caudate $(n=17)$ and $6.6 \pm 2.9$ spikes $/ \mathrm{sec}$ in control caudate $(n=17)$.

DA and APO, both dissolved in saline, were pressure-ejected from separate barrels of the same pipette assemblies. Effects of either agonist were compared in the same rat on lesioned and unlesioned caudates; the object of the experiment was to demonstrate changes in sensitivity to the agonist induced by denervation, and their possible reversibility by haloperidol. Results of these dose-response studies are shown in Figure 7. Before haloperidol, the $\mathrm{ED}_{50}$ of APO in caudate lesioned with 6-OHDA was significantly less than the $\mathrm{ED}_{50}$ in control caudatc. However, after haloperidol, the $\mathrm{ED}_{50}$ of APO in lesioned caudate was not significantly different from the $\mathrm{ED}_{50}$ in control caudate. Similarly, before haloperidol, the $\mathrm{ED}_{50}$ of $\mathrm{DA}$ in lesioned caudate was significantly less than the $\mathrm{ED}_{50}$ in control caudate. However, after haloperidol, the $\mathrm{ED}_{50}$ in lesioned caudate was not significantly different from the $\mathrm{ED}_{50}$ in control caudate.

\section{Discussion}

We considered several possible explanations for why previous investigators (Ben-Ari and Kelly, 1976; Skirboll and Bunney, 1979; Zarzecki et al., 1977) failed to demonstrate that the inhibitory effects of DA applied locally to striatal neurons could be antagonized by neuroleptic agents administered systemically. Although previous investigators used microiontophoresis to deliver dopamine, and artifacts associated with this procedure could have in some way interfered with the experiment, this technical factor is an unlikely source of the anomaly, since in our study micropressure ejection also did not demonstrate blockade. Also, our use of ascorbate to prevent oxidation of DA, which was not utilized by previous investigators, did not affect the outcome of these experiments. Failure to observe blockade cannot be due to a peculiarity of a single species of laboratory animal, since previous experiments were performed with both cats (Ben-Ari and Kelly, 1976; Zarzecki et al., 1977) and rats (Skirboll and Bunney, 1979). Finally, problems arising from anesthetic protocols can be minimized, since past investigators used a variety of anesthetic agents, including pentobarbital (Zarzecki et al., 1977) halothane/ $\mathrm{N}_{2} \mathrm{O}$ (Ben-Ari and Kelly, 1976), and gallamine-induced paralysis (Skirboll and Bunney, 1979).

One potential factor we investigated was whether observation of antagonism might be possible only at the time of peak effect of the neuroleptic agent. In agreement with results from others (Moller-Nielsen et al., 1973), we found that haloperidol has a long time course of action, with maximal cataleptic effect 2-4 hr after i.p. administration. Because it is difficult to record continuously from a single neuron for longer than an hour, the long time course of haloperidol virtually precluded any attempt to study neuronal recovery from neuroleptic drug action. We therefore employed a technique in which a control animal and an animal treated with haloperidol were paired, and the potency of DA released from the micropipette was assessed concurrently in control and drug-treated animals. However, despite use of this "paired"-animal technique and longer time courses, we were still unable to demonstrate antagonism of locally applied DA.

We next explored the possibility that DA endogenous to the striatum interferes in some way with antagonism by haloperidol of locally applied exogenous DA. For example, locally applied dopamine might interact with presynaptic dopaminergic receptors to decrease release of endogenous DA or it might be taken up into terminals and thus inactivated. Alternatively, systemically administered haloperidol might block autoreceptors in the substantia nigra (Aghajanian and Bunney, 1977) and thus 


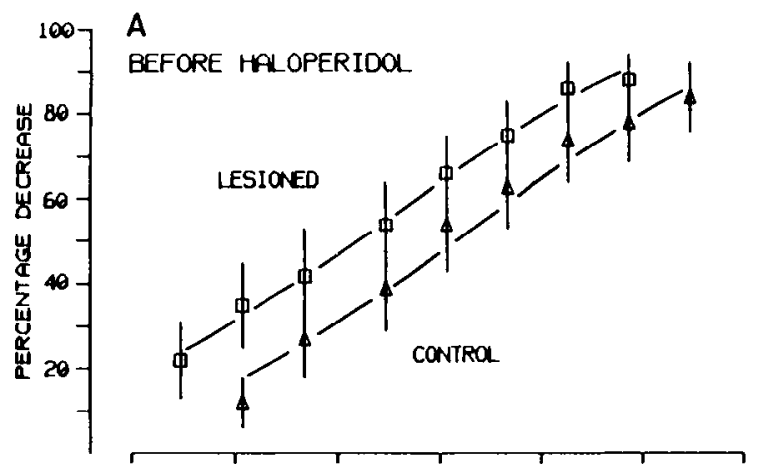

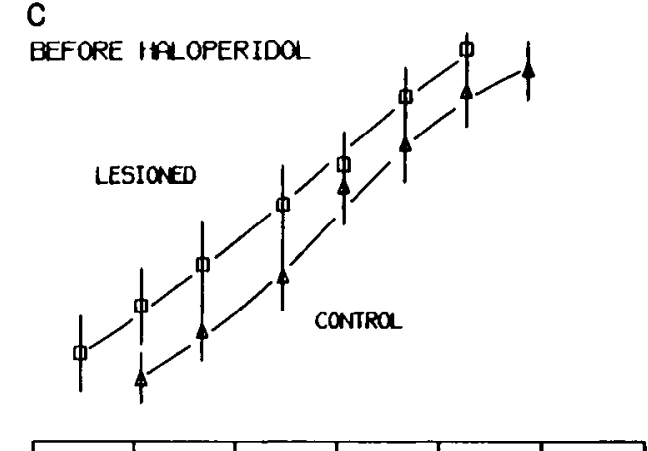

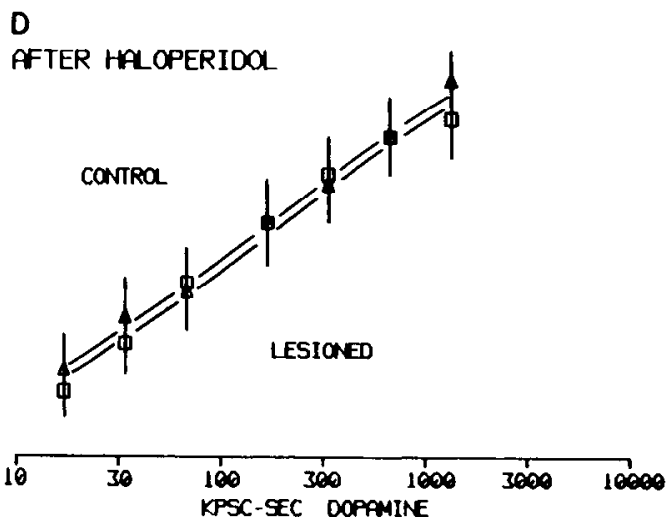

Figure 7. Dose-related effects of apomorphine (APO; left side) and dopamine (DA; right side) on spontaneous activity of caudate neurons in rats with unilateral 6-OHDA lesions. APO and DA were pressure-ejected from separate barrels of 14 three-barrel micropipette assemblies (seven before and seven after haloperidol). Effects of APO and DA were tested on the same population of neurons recorded before and after haloperidol (1 mg/ $\mathrm{kg}$, i.p.) ir each of four rats. Each pipette was used to record neurons from control and lesioned caudates, as described in Methods. Neurons were recorded $3.1 \pm 1.7 \mathrm{hr}(\bar{X} \pm \mathrm{SD})$ after haloperidol injection. $A$, Before haloperidol, the $\mathrm{ED}_{50}$ (and 95\% confidence limits) of APO in control caudate was $369(279-488) \mathrm{kPa}-\mathrm{sec}$, and was $113(95-135) \mathrm{kPa}-\mathrm{sec}$ in lesioned caudate. Thus, there was a significant difference in potency, with a potency ratio of 3.3. $B$, After haloperidol, APO was no longer more potent in lesioned than in control caudate. $C$, DA was significantly more potent in lesioned caudate before haloperidol, with an $\mathrm{ED}_{50}$ of 103 (75-141) $\mathrm{kPa}-\mathrm{sec}$ compared to 253 (223-288) $\mathrm{kPa}$-sec in control caudate. The potency ratio was 2.5. $D$, After haloperidol, the potency ratio was 0.7 , reflecting no significant increase in DA potency on the lesioned side.

block uptake or cause release of DA from terminals in the caudate. Two strategies were used to try to obviate this potential problem. First, we used $A P O$ as an alternative postsynaptic agonist, since it is not taken up into dopaminergic terminals. Unfortunately, haloperidol also failed to antagonize locally applied APO, although inhibitions of caudate neuronal activity were antagonized when APO was administered parenterally. The second strategy was to reduce levels of endogenous dopamine by utilizing animals pretreated with reserpine and $\alpha$-methyl-paratyrosine. Acute treatment with these agents were used, rather than a lesion technique, to minimize confounding effects of postsynaptic supersensitivity. However, in these animals pretreated with reserpine and $\alpha$-methyl-paratyrosine, haloperidol still failed to antagonize locally applied DA.

At this point in our investigation, we explored the ability of haloperidol to block effects of an agent that acts indirectly as a DA agonist, PCP. PCP has been demonstrated by ourselves (Johnson et al., 1984) and others to produce DA-like effects in striatum by virtue of causing release of DA from nerve terminals or by preventing reuptake of DA (Ary and Komiskey, 1982; Garey and Heath, 1976; Kanner et al., 1981). The evidence supporting the use of PCP as a specific indirect catecholamine agonist, despite its well-known anesthetic and anticholinergic actions, is detailed in Johnson et al. (1984) and Bickford et al. (1982). Briefly, its effects on caudate neurons are antagonized by 6-OHDA lesions of substantia nigra, by catccholaminc depletion, by reserpine and $\alpha$-methyl-paratyrosine, and by blockade of synaptic transmission by iontophoresis of magnesium ion.

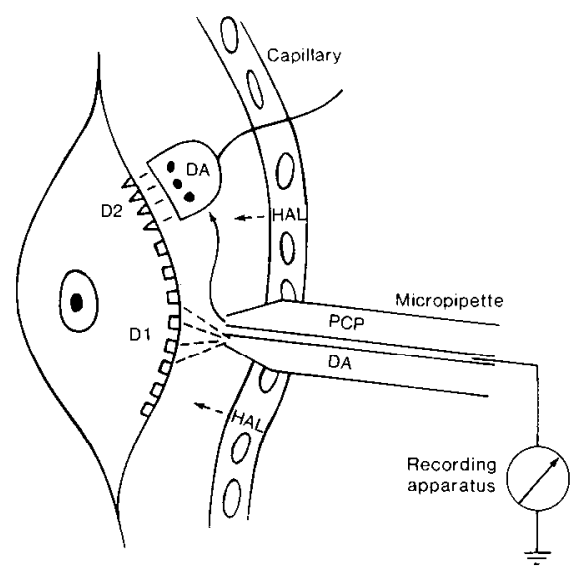

Figure 8. Schematic diagram showing the interaction between agonists applied from a multibarreled pipette and haloperidol delivered systemically. Dopamine $(D A)$ applied from the micropipette in a short burst primarily contacts putative $D I$ receptors, located extrasynaptically on the caudate neuron. Phencyclidine $(P C P)$, an indirect agonist, acts only on dopaminergic nerve terminals. DA from these terminals contacts putative D2 receptors, which are the postsynaptic receptors. Haloperidol ( $H A L$ ) diffuses from capillaries to contact both D1 and D2 receptors; the concentration of HAL is sufficient to block DA at D2, but not D1 receptors. 
The results obtained with PCP and haloperidol in this study can be explained by the model shown diagrammatically in Figure 8 . It has been hypothesized that caudate neurons have two classes of dopaminergic receptors (Creese et al., 1983; Kebabian and Calne, 1979). The D2 receptors are most closely associated with DA synapses, and they have higher affinity for haloperidol than D1 types. They also increase in number after lesion of DA synapses. The DI receptors have lower affinity for haloperidol, and they do not increase after lesion of DA synapses. They might be termed "extrasynaptic." In our model, release of a small burst of DA from the pipette activates D1 receptors. Whether this preferential activation reflects the presence of a greater number of D1 receptors or whether access to D2 receptors is partly restricted by the synapse itself is unclear. This activation of D1 receptors is not blocked by parenterally administered haloperidol, which reaches these receptors in concentrations too low for antagonism. Locally applied haloperidol, on the other hand, could be administered in high enough concentrations to block the lower-affinity D1 receptors at the site of local DA application. PCP, as an indirect agonist, causes endogenous DA to activate D2 receptors preferentially. This action is blocked by parenterally administered haloperidol, because the concentration required for antagonism is less for the higher-affinity D2 receptors than for the lower-affinity D1 receptors. Therefore, parenterally administered haloperidol blocks locally administered PCP, an indirect agonist, but not DA, a direct agonist. Although we cannot determine definitely if equal amounts of exogenous and endogenous DA contact postsynaptic receptors in these experiments, the mean depression of caudate neuron activity was not significantly different for any agonist studied, which suggests that the agonist effects were similar.

Parenterally administered apomorphine, like parenterally administered haloperidol, would also diffuse from brain blood vessels to rcach low concentrations at both D1 and D2 receptors. At these low concentrations, D2 receptors are activated preferentially because of their higher affinity for APO. When APO is administered locally, however, it preferentially activates D1 receptors, as DA did. Thus, parenterally, but not locally, administered APO is antagonized by parenterally administered haloperidol.

The anomalies observed with DA agonists and antagonists when parenteral and local administration are compared are thus hypothesized to reflect two factors: first, the heterogeneity of caudate DA receptors and, second, the restricted access of brief bursts of locally applied direct agonists to D2 receptors. As a test of this hypothesis, we performed experiments with DA and APO in caudates in which the DA input pathway has been lesioned with 6-OHDA. We predicted that the numbers of D2 receptors should be increased and now be more accessible to locally applied agonist, although D1 receptors would also be activated. Only the D2 component should be sensitive to haloperidol. The results obtained were in accord with the model's prediction: Sensitivity to DA increased in the lesioned animals and this increase, but not the basal response, was blocked by parenterally administered haloperidol. Furthermore, neurons in 6-OHDA-lesioned caudates fired significantly faster than those in nonlesioned caudate, an effect that disappeared after haloperidol treatment. This finding suggests that a low level of release of endogenous DA onto $\mathrm{D} 2$ receptors in the nonlesioned caudate is blocked by haloperidol. The inhibitory effects of endogenous DA are responsible for the lower spontaneous discharge in nonlesioned caudates as compared to the 6-OHDA-denervated caudate; this difference disappears when haloperidol is administered at doses that block D2 receptors. Since we did not rigorously identify the neurons in either control or 6-OHDA-lesioned animals, it should be noted that the increased sensitivity to DA in 6-OHDA-lesioned animals could represent disinhibition of previously silent neurons that are more sensitive to
DA than the spontaneously active neurons observed in control animals.

The different results obtained with PCP and amphetamine require further comment. Amphetamine is classically an indirect agonist (Weiner, 1972); generally its electrophysiological effects in caudate after parenteral administration disappear with lesion of catecholamine pathways by 6-OHDA (Groves et al., 1975). Despite this clear role as an indirect agonist, locally administered amphetamine has been shown in five studies to have direct effects after amine depletion or lesion of dopaminergic (Felt7. and de Champlain, 1972; Stone, 1976) or noradrenergic (Hoffer et al., 1971, 1975; Kostopoulos and Yarbrough, 1974) circuits. PCP, on the other hand, has no direct dopaminergic (Johnson et al., 1984) or noradrenergic (Marwaha et al., 1980) effects, even when applied locally to 6-OHDA-lesioned animals. Amphetamine's direct effects, like those of locally applied DA, may be caused by its interaction at high concentration with extrasynaptic receptors. These interactions would not be blocked by haloperidol parenterally administered, as was found here. Since PCP, unlike amphetamine, does not share structural characteristics with catecholamines, it has no direct effects, and its indirect effects are antagonized by haloperidol.

\section{References}

Aghajanian, G. K., and B. S. Bunney (1977) Dopamine "autoreceptors": Pharmacological characterization by microiontophoretic single cell recording studies. Naunyn Schmiedebergs Arch. Pharmacol. 297: $1-7$.

Anden, N. E., A. Rubenson, K. Fuxe, and T. Hokfelt. (1967) Evidence for dopamine receptor stimulation by apomorphine. J. Pharm. Pharmacol. 19: 627-629.

Ary, T. E., and H. L. Komiskey (1982) Phencyclidine-induced release of ${ }^{3} \mathrm{H}$-dopamine from chopped striatal tissue. Neuropharmacology 21: 639-645.

Bacopoulos, N. G., and R. H. Roth (1981) Apomorphine-haloperidol interactions: Different types of antagonism in cortical and subcortical brain regions. Brain Res. 205: 313-319.

Bagchi, S. P. (1981). Effects of phencyclidine on synaptosomal dopamine continuously appearing from phenylalanine: Sensitivity to reserpine. Neuropharmacology 20: 845-851.

Ben-Ari, Y., and J. S. Kelly (1976) Dopamine evoked inhibition of single cells of the feline putamen and basolateral amygdala. J. Physiol. (Lond.) 256: 1-22.

Bickford, P., M. R. Palmer, B. I. Hoffer, and R. Freedman (1982) Interactions of phencyclidine with cholinergic excitations of hippocampal pyramidal neurons. Neuropharmacol. 21: 729-732.

Carlsson, A., and M. Lindquist (1953) Effect of chlorpromazine or haloperidol on formation of 3-methoxytyramine and normetanephrine in mouse brain. Acta Pharmacol. Toxicol. 10: 140-144.

Changeux, J. P., and T. R. Podleski (1968) On the excitability and cooperativity of the clectroplax membranc. Proc. Natl. Acad. Sci. USA 59: 944-950.

Clement-Cormier, Y.C., J. W. Kebabian, G. L. Petzold, and P. Greengard (1974) Dopamine-sensitive adenylate cyclase in mammalian brain: A possible site of action of antipsychotic drugs. Proc. Natl. Acad. Sci. USA 71: 1113-1117.

Creese, I., D. R. Burt, and S. H. Snyder (1976) Dopamine receptor binding predicts clinical and pharmacological potencies of antischizophrenic drugs. Science 192: 481-483.

Creese, I., D. R. Sibley, M. W. Hamblin, and S. E. Leff (1983) The classification of dopamine receptors: Relationship to radioligand binding. Annu. Rev. Neurosci. 6: 43-71.

Feltz, P., and J. de Champlain (1972) Enhanced sensitivity of caudate neurones to microiontophoretic injections of dopamine in 6-hydroxydopamine treated cats. Brain Res. 43: 601-605.

Garey, R. E., and R. G. Heath (1976) The effects of phencyclidine on the uptake of ${ }^{3} \mathrm{H}$-catecholamines by rat striatal and hypothalamic synaptosomes. Life Sci. 18: 1105-1110.

Groves, P. M., G. V. Rebec, and J. A. Harvey (1975) Alterations of the effects of $(+)$-amphetamine on neuronal activity in the striatum following lesion of the nigrostriatal bundle. Neuropharmacology 14: 309-316. 
Heikkila, R. E., B. S. Shapiro, and R. C. Duvoisin (1981) The relationship between loss of dopamine nerve terminals, striatal ${ }^{3} \mathrm{H}$-spiroperidol binding and rotational behavior in unilaterally 6-hydroxydopamine-lesioned rats. Brain Res. 211: 285-292.

Hcikkila, R. E., F. S. Cabbat, and L. Manzino (1982) Inhibitory cffects of ascorbic acid on the binding of ${ }^{3} \mathrm{H}$-dopamine antagonists to neostriatal membrane preparations: Relationship to lipid peroxidation. J. Neurochem. 38: 1000-1006.

Hoffer, B. J., G. R. Siggins, and F. E. Bloom (1971) Studies on norepinephrine containing afferents to Purkinje cells of rat cerebellum. II. Sensitivity of Purkinje cells to norepinephrine and related substances administered by microiontophoresis. Brain Res. 25:522-534.

Hoffer, B., L. Olson, A. Seiger, and F. Bloom (1975) Formation of a functional adrenergic input to intraocular cerebellar grafts: Ingrowth of sympathetic fibers and inhibition of Purkinje cell activity by adrenergic input. J. Neurobiol. 6:565-586.

Janssen, P. A. J. (1973) Structure-activity relationships (SAR) and drug design as illustrated with neuroleptic agents. In Structure-Activity Relations, Vol. 1, Sect. 5, C. J. Cavallito, cd., pp. 37-73, International Encyclopedia of Pharmacology and Therapeutics, Pergamon, Oxford, UK.

Johnson, S. W., M. R. Palmer, and R. Freedman (1983) Effects of dopamine on spontaneous and evoked activity of caudate neurons. Neuropharmacology 22: 843-851.

Johnson, S. W., P. E. Haroldsen, B. J. Hoffer, and R. Freedman (1984) Presynaptic dopaminergic activity of phencyclidine in rat caudate. J. Pharmacol. Exp. Ther. 229: 322-332.

Kanner, M., K. Finnegan, and H. Y. Meltzer (1981) Dopaminergic effects of phencyclidine in rats with nigrostriatal lesions. Neurology 31: 434-439.

Kebabian, J. W., and D. B. Calne (1979) Multiple receptors for dopamine. Nature 227: 93-96.

Kolbe, H., A. Clow, P. Jenner, and C. D. Marsden (1981) Neurolepticinduced acute dystonic reactions may be due to enhanced dopamine release on to supersensitive postsynaptic receptors. Neurology 31 : 434-439.

Kostopoulos, G. K., and G. G. Yarbrough (1974) Iontophoretic studies with 'false transmitters' on cerebellar Purkinje cells. Br. J. Pharmacol. 52: 136.

Marshall, J. F., and H. Ungerstedt (1977) Supersensitivity to apomorphine following destruction of the ascending dopamine neurons. Quantification using the rotational model. Eur. J. Pharmacol. 41:351367.

Marwaha, J., M. R. Palmer, D. J. Woodward, R. J. Hoffer, and R. Freedman (1980) Electrophysiological evidence for presynaptic actions of phencyclidine on noradrenergic transmission in rat cerebellum. J. Pharmacol. Exp. Ther. 215: 606-613.

McCaman, R. E., D. G. McKenna, and J. K. Ono (1977) A pressure system for intracellular ejections of picoliter volumes. Brain Res. 136: 141-147.
Miller, R. H., A. S. Horn, and L. L. Iversen (1974) The action of neuroleptic drugs on dopamine-stimulated adenosine cyclic $3^{\prime}, 5^{\prime}$ monophosphate phosphate production in rat neostriatum and limbic forebrain. Mol. Pharmacol. 10: 759-766.

Moller-Nielsen, I., V. Pedersen, M. Nymark, K. F. Franck, V. Boeck, B. Fjalland, A. V. Christensen (1973) The comparative pharmacology of flupenthixol and some reference neuroleptics. Acta Pharmacol. Toxicol. 33: 353-362.

Palmer, M. R., and B. J. Hoffer (1980) Catecholamine modulation of enkephalin-induced electrophysiological responses in cerebral cortex. J. Pharmacol. Exp. Ther. 213: 205-215.

Palmer, M. R., S. M. Wuerthele, and B. J. Hoffer (1980) Physical and physiological characteristics of micropressure ejection of drugs from multibarreled pipettes. Neuropharmacology 19: 931-938.

Pellegrino, L. J., A. S. Pellegrino, and A. J. Cushman (1979) A Stereotaxic Atlas of the Rat Brain, 2nd Ed., Plenum, New York.

Perlow, M. J., W. J. Freed, B. J. Hoffer, A. Seiger, L. Olson, and R. J. Wyatt (1979) Brain grafts reduce motor abnormalities produced by destructive nigrostriatal dopamine system. Science 204: 643-647.

Sakai, M., B. E. Schwartz, and C. D. Woody (1979) Controlled microrelease of pharmacological agents: Measurements of volumes ejected in vitro through fine tipped glass microelectrodes by pressure. Neuropharmacology 18: 209-213.

Siggins, G., B. Hoffer, and U. Ungerstedt (1974) Electrophysiological evidence for the involvement of cyclic adenosine monophosphate in dopamine responses of caudate neurons. Life Sci. 15: 779-792.

Skirboll, L. R., and B. S. Bunney (1979) The effects of acute and chronic haloperidol treatment on spontaneously firing neurons in the caudate nucleus of the rat. Life Sci. 25: 1419-1434.

Stone, T. W. (1976) Responses of neurones in the cerebral cortex and caudate nucleus to amantadine, amphetamine and dopamine. $\mathrm{Br}$. J. Pharmacol. 56: 101-110.

Tallarida, R. J., and L. S. Jacob (1979) The Dose-Response Relations in Pharmacology, pp. 85-110, Springer-Verlag, New York.

Ungerstedt, U., and G. W. Arbuthnott (1970) Quantitative recording of rotational behavior in rats after 6-hydroxydopamine lesions of the nigrostriatal dopamine system. Brain Res. 24: 485-493.

Ungerstedt, U., and T. Ljungberg (1974) Central dopamine neurons and sensory processing. J. Psychiat. Res. 11: 149-156.

Vickroy, T. W., and K. M. Johnson (1983) Effects of phencyclidine on the release and synthesis of newly formed dopamine. Neuropharmacology 22: 839-842.

Weiner, N. (1972) Pharmacology of central nervous system stimulants. In Drug Abuse: Proceedings of the International Conference, C. J. D. Zarafonetis, ed., pp. 243-251, Lea \& Febiger, Philadelphia.

York, D. H. (1972) Dopamine receptor blockade: A central action of chlorpromazine on striatal neurons. Brain Res. 37: 91-99.

Zarzecki, P., D. J. Blake, and G. Somjen (1977) Neurological disturbances, nigrostriate synapses, and iontophoretic dopamine and apomorphine after haloperidol. Exp. Neurol. 57: 956-970. 